\title{
Anatomic Stage III Breast Cancer AJCC v8
}

National Cancer Institute

\section{Source}

National Cancer Institute. Anatomic Stage III Breast Cancer A/CC v8. NCI Thesaurus. Code C139541.

Stage III includes: IIIA: (T0, N2, M0); (T1, N2, M0); (T2, N2, M0); (T3, N1, M0); (T3, N2, M0); IIIB: (T4, N0, M0); (T4, N1, M0); (T4, N2, M0); IIIC: (Any T, N3, M0). T0: No evidence of primary tumor. T1: Tumor measuring $20 \mathrm{~mm}$ or less in greatest dimension. T2: Tumor measuring more than $20 \mathrm{~mm}$, but not more than $50 \mathrm{~mm}$ in greatest dimension. T3: T umor measuring more than $50 \mathrm{~mm}$ in greatest dimension. T4: T umor of any size with direct extension to the chest wall and/or to the skin (ulceration or macroscopic nodules); invasion of the dermis alone does not qualify as T4. N0: No regional lymph node metastasis is identified or isolated tumor cell clusters (ITCS) are identified only. N1: Tumor with micrometastases; or metastases in 1-3 axillary lymph nodes; and/or clinically negative internal mammary nodes with micrometastases or macrometastases by sentinel lymph node biopsy. N2: Tumor with metastases in 4-9 axillary lymph nodes; or positive ipsilateral internal mammary lymph nodes by imaging in the absence of axillary lymph node metastases. N3: T umor with metastases in 10 or more axillary lymph nodes; or in infraclavicular (level III axillary) lymph nodes; or positive ipsilateral internal mammary lymph nodes by imaging in the presence of one or more positive level I, II axillary lymph nodes; or in more than three axillary lymph nodes and micrometastases or macrometastases by sentinel lymph node biopsy in clinically negative ipsilateral internal mammary lymph nodes; or in ipsilateral supraclavicular lymph nodes. M0: No clinical or radiographic evidence of distant metastases. Imaging studies are not required to assign the M0 category. (AJCC 8th ed.) 